\title{
The carbon footprint of large astronomy
} \section{meetings}

The annual meeting of the European Astronomical Society took place in Lyon, France, in 2019, but in 2020 it was held online only due the COVID-19 pandemic. The carbon footprint of the virtual meeting was roughly 3,000 times smaller than the face-to-face one, providing encouragement for more ecologically minded conferencing.

\section{Leonard Burtscher, Didier Barret, Abhijeet P. Borkar, Victoria Grinberg, Knud Jahnke, Sarah Kendrew, Gina Maffey and Mark J. McCaughrean}

T he scientific evidence that we live in a climate emergency calls for urgent action ${ }^{1}$. As a society, we are collectively failing to live within our environmental boundaries, with possibly catastrophic consequences for human civilization $^{1}$. The time to address these issues is now ${ }^{1,3}$. The United Nations Emissions Gap Report from 2019 states that each year a global reduction of emissions of $7.6 \%$ is required to limit the average global temperature rise to $1.5^{\circ} \mathrm{C}$ (ref. ${ }^{3}$ ) - the target that was outlined in the Paris Agreement in 2016. At the current rate of emissions, we will exceed the 'carbon budget' to meet this goal within the next eight years ${ }^{4}$.

While ultimately systemic change is required to solve the climate crisis, it is also the responsibility of individuals to reduce our emissions. This applies in particular to astronomers who rely heavily on fossil fuel energy for, for example, computation, telescope operation and travel ${ }^{5-8}$. To future-proof astronomy, we must recognize impending environmental change, financial uncertainties and the need for moral introspection, which threaten to hinder the continuation of the discipline. At the same time, the advancement and sharing of knowledge in general (and particularly with the public) is becoming even more vital as we face a global threat.

\section{EWASS 2019 equivalent emissions}

Conferences are a vital element of astrophysical research and collaboration, but the air travel often connected with face-to-face conferences is a major source of environmental concern. Following last year's annual European Astronomical Society (EAS) meeting in Lyon (the European Week of Astronomy and Space Science (EWASS) 2019), we conducted a short survey among participants who had agreed to receive such communication via e-mail (719 out of 1,240 attendees) to estimate the current, collective carbon emissions generated through travel

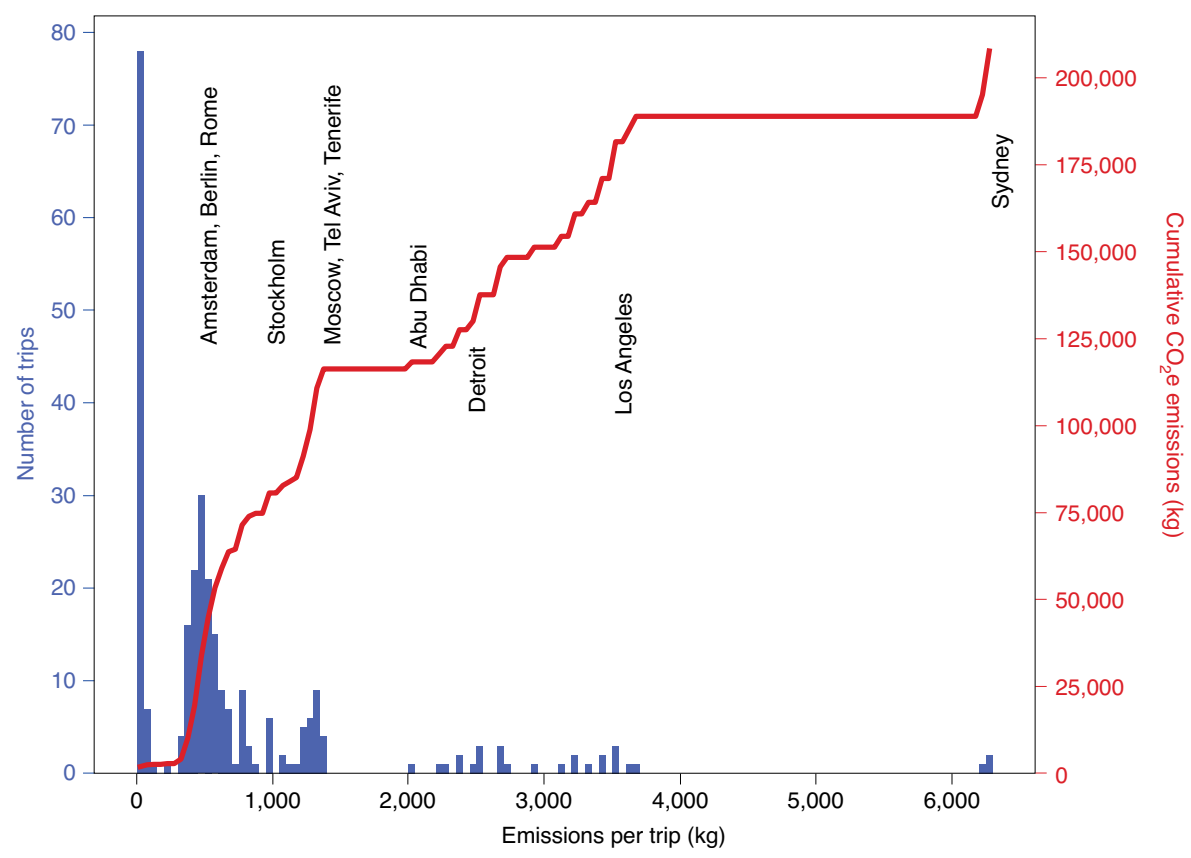

Fig. 1 | Histogram of $\mathrm{CO}_{2} \mathrm{e}$ emissions per trip. The blue histogram corresponds to the left axis, and cumulative emissions are shown with the red line and the right axis. Some example destinations are indicated for reference. Note that these numbers refer to respondents only ( $22 \%$ of all participants).

to and from the meeting. In establishing this initial estimate as a baseline, it was hoped that guidance could be developed to reduce future travel-related emissions. The anonymous questionnaire was very simple and only asked for the participants' origin and final destination and their main mode of transport. After two weeks we had collected 267 (22\% of all participants) valid responses.

Just over two thirds of the respondents (66.9\%) indicated that they arrived in Lyon by airplane, $27.8 \%$ arrived by train and the remaining $5.3 \%$ used other means of transport such as car, bus, metro, bike or by foot. $86.5 \%$ returned directly to their origin after the conference using the same means of transport. Of those who did not, the modal split was similar to the inbound journey.

We computed the $\mathrm{CO}_{2}$-equivalent $\left(\mathrm{CO}_{2} \mathrm{e}\right)$ emissions associated with every plane or train trip using an online travel footprint calculator with its default settings, and we refer the reader to the accompanying paper ${ }^{9}$ for a discussion on the pitfalls of the methods used in these calculations (for example, assumptions about the radiative forcing index). For car trips, we used Google Maps to compute the shortest road distance and assumed emissions of $110 \mathrm{~g} \mathrm{~km}^{-1}$ (ref. ${ }^{10}$ ). The result of this computation is shown in Fig. 1.

The majority of trips $(\sim 80 \%)$ produced $\mathrm{CO}_{2} \mathrm{e}$ emissions of less than $1,000 \mathrm{~kg}$ per 


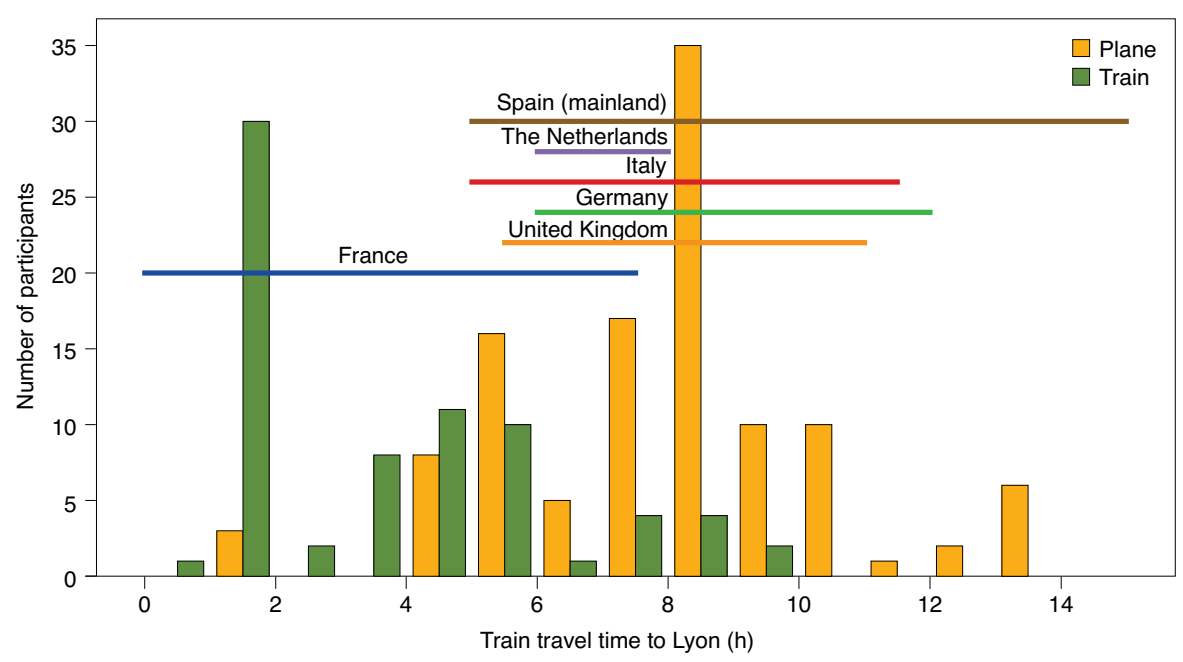

Fig. 2 | Actual or hypothetical train travel time to Lyon for all European participants who actually travelled by train (green) or could have travelled by train but took the plane (orange). Train travel times for the six countries with most participants are indicated as horizontal bars. Note that these numbers refer only to those participants who responded to the survey ( $22 \%$ of all participants).

trip. Conversely, the intercontinental flights ( $10 \%$ of all trips) produced $50 \%$ of the total emissions of respondents.

In addition, we also looked up the equivalent train travel time for all European travellers who arrived by plane, except for those where a train connection does not (currently) exist. This resulted in 159 theoretically possible train connections. 135 (85\%) of these would take less than 24 hours; 114 (72\%) would take less than 15 hours. We show a histogram of the latter together with the (looked up) train travel times for those 74 respondents who actually journeyed by train in Fig. 2.

From additional data shared by the EAS, we know that $\sim 84 \%$ of all participants (not just survey respondents) came from European destinations, which are almost all accessible by train. The majority of EWASS 2019 participants could therefore have travelled to Lyon by train if they could have devoted more (working) time to travel. It is important to note that a two-hour flight usually converts into at least four hours of door-to-door travel time, of which only a small fraction of time can be used for productive work. On the other hand, the median train travel time for those $85 \%$ of participants who could have travelled by train was eight hours. Most of this time can be used productively for work, especially if travelling in modern trains that are equipped with power sockets and reliable Wi-Fi connections. A full week of conferencing (Monday, 9 am till Friday, $5 \mathrm{pm}$ ) requires flexibility for the participants to spend weekend days for travel, which may not always be possible and works against the typically longer journey when travelling by train. Another obstacle for choosing the train over the plane is the often higher costs of train tickets compared to equivalent airfares. This does not reflect the real costs of both modes of transport since air fares do not include VAT or taxes on energy, and also do not usually include compensation for the substantial environmental damage that airplanes create. Positively, some universities, including the Dutch universities of Leiden and Groningen and the Belgian university of Ghent, already have environment-friendly travel policies in place that require researchers to take the train for connections that take less than six hours and recommend taking the train for connections that take up to eight hours.

Lastly, we estimated the total travel emissions associated with EWASS 2019 by correcting, country-per-country, for incompleteness in our survey responses. For example, to compute the total travel emissions for all Dutch participants, we computed the average emissions of Dutch respondents for both their outbound and return trip $(673 \mathrm{~kg})$ and multiplied this by the total number of participants from this country (78). This assumes a similar modal split (plane vs. train) for those participants who did not fill in the travel survey. The total travel emissions for all 1,240 participants is then an estimated $1,855 \mathrm{tCO}_{2} \mathrm{e}$. This is of the same order of magnitude as the yearly emissions of a medium-sized astronomical research institute (for example, the emissions of the
Max Planck Institute for Astronomy (MPIA) in Heidelberg ${ }^{11}$ were 2,720 $\mathrm{tCO}_{2} \mathrm{e}$ in 2018). The average per capita travel emissions for EWASS $2019(1.5 \mathrm{t})$ are also comparable to the average annual per capita emissions of developing countries (for example, India, at $1.8 \mathrm{t}$; ref. ${ }^{12}$ ). It gives a sense of the scale of the problem and the responsibility that we have that the additional emissions burden involved in one average astronomer participating in a single conference in Europe is roughly equal to the average total annual per capita emissions in India.

We note that our brief analysis does not include other emissions or waste associated with single-use items (such as plastic bottles, conference booklets, and other giveaways), extra food production, energy for the conference venue building, and so on. We estimate that these factors are only a small fraction of the travel-related emissions, however (based, for example, on the analysis of Jahnke et al. on the carbon footprint of the MPIA ${ }^{11}$ ).

\section{EAS 2020 equivalent emissions}

We can also compare the EWASS 2019 travel emissions to EAS 2020, the first online-only version of the EAS's annual meeting. With 1,777 participants, EAS 2020 was the largest online astronomy meeting to date - a change that impacted not only carbon emissions, but also diversity and inclusivity, as a forthcoming article will illustrate.

681 out of 1,777 participants (38\%) answered the EAS 2020 exit survey and of those, $57 \%$ said they would have taken the plane if they had travelled to Leiden. This number is lower than last year's (67\%) which may be connected to the fact that Leiden (via Rotterdam or Utrecht) is well connected to the high-speed rail network (with direct connections to Paris, Brussels, London, Cologne and Frankfurt). Nevertheless, this result may also give reason to hope that astronomers are becoming more aware of the environmental damage that flying causes.

Of course, EAS 2020 was not entirely carbon-neutral either, since virtual conferencing consumes a considerable amount of electrical energy both at the end user's site and for running the network infrastructure (and servers). A simple estimation can be made based on the fraction of people joining each of the five days of the conference $(\sim 80 \%$, based on the exit survey), the number of hours people were online per day ( 5.5 hours, based on the exit survey), the data rate of a Zoom webinar $\left(1.2 \mathrm{Mbps}\right.$ downstream $\left.{ }^{13}\right)$ and the electricity use per gigabyte transferred over the internet $\left(0.06 \mathrm{kWh} \mathrm{GB}^{-1}\right.$ for $\left.2015^{14}\right)$. In addition, electrical energy is required for running the 


\section{Box 1 | Estimation of carbon emissions of EAS 2020}

\section{Network-related emissions}

5 days $\times 80 \%$ participation per day $\times 1,777$ participants $\times 5.5$ hours online per day $\times$ $1.2 \mathrm{Mbps} \times 3,600 \mathrm{~s} \mathrm{~h}^{-1} \times 1 / 8$ byte bit $^{-1} \times 1 / 1,024 \mathrm{~GB} \mathrm{MB}^{-1} \times 0.06 \mathrm{kWh} \mathrm{GB}^{-1}$ $\times 0.24 \mathrm{~kg} \mathrm{kWh}^{-1}=297 \mathrm{kgCO}_{2} \mathrm{e}$

\section{Laptop-related emissions}

5 days $\times 80 \%$ participation per day $\times 1,777$ participants $\times 5.5$ hours online per day $\times$ $30 \mathrm{~W} \times 1 / 1,000 \mathrm{~kW} \mathrm{~W}^{-1} \times 0.24 \mathrm{~kg} \mathrm{kWh}^{-1}=281 \mathrm{kgCO}_{2} \mathrm{e}$

\section{Zoom-server related emissions}

5 days $\times 10$ hours per day $\times 300 \mathrm{~W} \times 1 / 1,000 \mathrm{~kW} \mathrm{~W}^{-1} \times 0.24 \mathrm{~kg} \mathrm{kWh}^{-1}=3.6 \mathrm{kgCO}_{2} \mathrm{e}$

participants' laptops $(\sim 30 \mathrm{~W})$ and the Zoom server itself. For the latter we estimate that a single 24-core Xeon machine would suffice, which consumes approximately $300 \mathrm{~W}$ of electrical power. The total electrical energy consumption for EAS 2020 is then $1,173 \mathrm{kWh}$ (laptops), 1,263 kWh (network) and $15 \mathrm{kWh}$ (Zoom servers) - see Box 1. With the $\mathrm{CO}_{2} \mathrm{e}$ emission intensity for electricity generation $\left(240 \mathrm{gCO}_{2} \mathrm{e} \mathrm{kWh}^{-1}\right.$; ref. ${ }^{15}$ ), we arrive at a total carbon footprint for EAS 2020 of $582 \mathrm{~kg}$ - roughly the emissions of a single return trip by airplane from Liverpool to Lyon. Note that this estimation does not account for attendees' domestic electricity (for routers, computers, lighting, and so on that are assumed to be running anyway). $582 \mathrm{~kg}$ can therefore be seen as a conservative estimate of the added emissions of joining EAS 2020 compared to working in the

home office.

\section{The future of conferencing}

We conclude that the internet-related emissions of EAS 2020 were negligible compared to the travel-related emissions alone of EWASS 2019. This finding is in common with other recent estimates for large international conferences, for example, a virtual annual meeting of the American Geophysical Union (AGU) was calculated to emit less than $0.1 \%$ of the travel emissions of the face-to-face AGU 2019 meeting ${ }^{16}$.

One approach to cut emissions while retaining scientific and social connections globally is to 'attach' smaller satellite meetings to the large annual meetings of the respective regional astronomical societies. For example, the weeks before and after the (Northern Hemisphere) winter American Astronomical Society and (Northern Hemisphere) summer EAS meetings could be used for smaller meetings that are held in the vicinity, requiring minimal extra travel emissions to join them. A meeting schedule could be coordinated globally by the International Astronomical Union.
While such a concept would be the most similar to the way meetings were organized in pre-COVID-19 times, it would still produce a considerable (too large) amount of emissions given that intercontinental air travel accounts for a large share of travel emissions ( $50 \%$ at EWASS 2019).

A possible solution to retain the social 'buzz' of a large conference while reducing emissions to near zero is to hold global meetings synchronously at a number of regional hubs that can be reached by train. To ease train travel, meetings could be held in accessible locations (for example, near major train stations rather than out-of-the-way places) and meeting schedules could accommodate train travel by starting Monday afternoon and ending Friday at noon. This latter restriction may fall thanks to an increasing fleet of night trains across Europe at least and, in the future, short flights that can be powered by synthesized fuel or batteries. Such a scheme of regional hubs has been tried and evaluated as successful by various groups in the last year ${ }^{17,18}$.

Lastly, we also see a possibility to move to an entirely online meeting format without any (large) physical meetings in the future. Such meetings could be held in the 'nearly carbon neutral conferencing' format ${ }^{19}$, that is, essentially with pre-recorded talks and live discussion sessions, to minimize the time where everyone needs to be online simultaneously, and therefore allow global collaboration across many time-zones.

The emerging picture is that there is a real opportunity for future meetings to adopt practices that provide a range of attendance possibilities for participants, which promote a more sustainable, accessible and diverse meeting concept for the growing international community. While discussions are ongoing regarding the future of meetings, we expect that the post-COVID-19 future will hold a mix of purely virtual conferences, next to hybrid meetings where some participants join in person and others use a video connection. EAS 2021 is planned to be held in this way.

\section{Leonard Burtscher (D) 1ه, Didier Barret (D), Abhijeet P. Borkar (D) ${ }^{3}$, Victoria Grinberg (D) 4 , Knud Jahnke (D) ${ }^{5}$, Sarah Kendrew6 ${ }^{6}$, Gina Maffey ${ }^{7}$ and Mark J. McCaughrean ${ }^{8}$ ${ }^{1}$ Leiden Observatory, Leiden, The Netherlands. ${ }^{2}$ Centre National de la Recherche Scientifique, Institut} de Recherche en Astrophysique et Planétologie, Université de Toulouse, Toulouse, France. ${ }^{3}$ Astronomy Institute of the Czech Academy of Sciences, Prague, Czech Republic. ${ }^{4}$ Institut für Astronomie und Astrophysik, Universität Tübingen, Tübingen, Germany. ${ }^{5}$ Max-Planck-Institut für Astronomie, Heidelberg, Germany. ${ }^{6}$ European Space Agency, Space Telescope Science Institute, Baltimore, MD, USA. ${ }^{7}$ JIVE (The Joint Institute for Very Long Baseline Interferometry European Research Infrastructure Consortium), Dwingeloo, The Netherlands. ${ }^{8}$ European Space Agency, ESTEC, Noordwijk, The Netherlands.

$\bigotimes_{e \text {-mail: burtscher@strw.leidenuniv.nl }}$

Published online: 10 September 2020 https://doi.org/10.1038/s41550-020-1207-z

References

1. Lenton, T. M. et al. Nature 575, 592-595 (2019).

2. Steffen, W. et al. Science 347, 1259855 (2015)

3. Emissions Gap Report 2019 (United Nations Environment Programme, 2019); https://www.unenvironment.org/resources/ emissions-gap-report-2019

4. IPCC Special Report on Global Warming of $1.5^{\circ} \mathrm{C}$ (WMO, 2018); https://www.ipcc.ch/sr15/

5. Matzner, C. D. et al. Astronomy in a Low-Carbon Future (Zenodo, 2019); https://doi.org/10.5281/zenodo.3758549

6. Williamson, K., Rector, T. A. \& Lowenthal, J. Preprint at https://arxiv.org/abs/1907.08043 (2019).

7. Portegies Zwart, S. Nat. Astron. https://doi.org/10.1038/s41550020-1208-y (2020)

8. Flagey, N., Thronas, K., Petric, A., Withington, K. \& Seidel, M. J. Nat. Astron. https://doi.org/10.1038/s41550-020-1190-4 (2020).

9. Barret, D. Exp. Astron. 49, 183-216 (2020).

10. Emissions de CO2 Marche (CCFA, 2018); https://ccfa.fr wp-content/uploads/2018/07/fiche-pays-ccfa_co2.pdf.

11. Jahnke, K. et al. Nat. Astron. https://doi.org/10.1038/s41550-0201202-4 (2020).

12. Muntean, M. et al. Fossil $\mathrm{CO}_{2}$ Emissions of All World Countries: 2018 Report (Publications Office of the European Union, 2018); https://go.nature.com/3gd9xyI

13. Zoom Bandwidth Requirements (Zoom, accessed 19 August 2020); https://support.zoom.us/hc/en-us/articles/201362023.

14. Aslan, J., Mayers, K., Koomey, J. G. \& France, C. J. Ind. Ecol. 22 , 785-798 (2018).

15. Overview of Electricity Production and Use in Europe (EEA, 2018); https://go.nature.com/2Q5vQvX

16. Klöwer, M., Hopkins, D., Allen, M. \& Higham, J. Nature 583, 356-359 (2020).

17. Abbott, A. Nature 577, 13 (2020).

8. Reshef, O. et al. Nat. Rev. Mater. 5, 253-256 (2020).

19. Hiltner, K. A Nearly Carbon-neutral Conference Model (2020); https://hiltner.english.ucsb.edu/index.php/ncnc-guide/

Acknowledgements

L.B. would like to acknowledge discussions and feedback on a draft article from M. Baes, A. Burkert, R. L. Davies,

L. Kaper, S. Lucatello, S. Portegies Zwart, H. Röttgering and A. Schouten-Voskamp.

\section{Competing interests}

L.B. was a member of the local organizing committee of the EAS 2020 meeting. M.J.M. was a member of the scientific organizing committee of the EWASS 2019 meeting. The remaining authors declare no competing interests. 